\title{
Wissenschaft nähert sich der Werbung an
}

\author{
Die wissenschaftliche Literatur nimmt explosionsartig zu. Der Kampf um Aufmerksamkeit \\ und Mittel beeinflusst auch die Wissenschaftssprache.
}

\begin{abstract}
_ Alle in PubMed von 1974-2014 gelisteten Abstracts wurden auf die jährliche Häufigkeit von je 25 positiven, negativen und neutralen Wörtern hin untersucht. In der Zeitperiode 1974-1980 tauchte in 2\% der Abstracts eines der untersuchten positiven Wörter auf. Diese Häufigkeit war im Jahr 2014 auf 17,5\% gestiegen eine relative Zunahme von $880 \%$. Spitzenreiter waren „robust“, „novel“, „innovative“, und „unprecedented“, die um bis zu $15.000 \%$ zulegten.
\end{abstract}

Dieser Trend zeigte sich in allen $\mathrm{Me}$ dien, wenngleich er in den Journalen mit hohem Impact-Faktor weniger stark aus- geprägt war. Englische Muttersprachler verwendeten die positiven Wörter signifikant seltener als Autoren aus nichtenglischsprachigen Ländern.

Negative Wörter nahmen dagegen im selben Zeitvergleich nur von 1,3\% auf $3,2 \% \mathrm{zu}$, was immerhin einen relativen Anstieg von $257 \%$ bedeutete. Bei den neutralen Wörtern fand sich kein derartiger Trend, ebensowenig bei zufällig ausgewählten Wörtern. Auch eine Analyse von stichprobenartig ausgewählten Büchern aus den gleichen Zeitperioden fand keine mit den Zeitschriften vergleichbaren Auffälligkeiten.
- Vinkers CH et al. Use of positive and negative words in scientific PubMed abstracts between 1974 and 2014: retrospective analysis. BMJ. 2015;351:h6467

\section{KOMMENTAR}

Die wahrscheinlichste Erklärung ist der wachsende Wettbewerb um Bedeutung und Publizität und letztlich um Fördermittel für die Wissenschaft. Die Mechanismen des "survival of the fittest" zwingen akademische Forscher in die Rolle eines Verkäufers. Um die besten Köpfe in der Forschung zu halten, bräuchten wir eine neue akademische Kultur, in der Qualität vor Quantität geht und man auch mal ohne Strafe scheitern kann.

Prof. Dr. med. H. S. FüeßI

\section{Kopfhautnekrosen bei Riesenzellarteriitis}

Ein 74-jähriger Mann stellte sich wegen seit drei Monaten bestehender Kopfschmerzen, Kiefer-

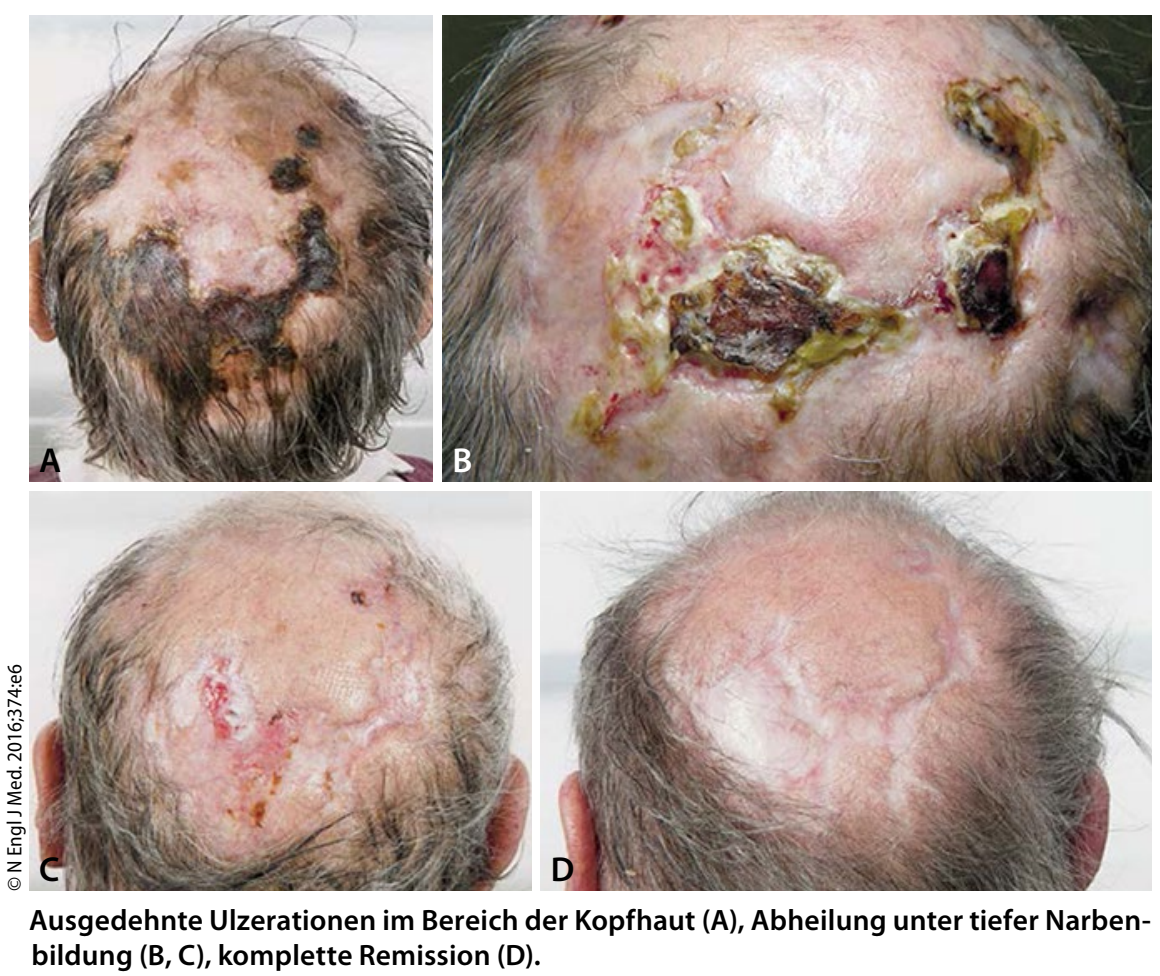

Ausgedehnte Ulzerationen im Bereich der Kopfhaut (A), Abheilung unter tiefer Narbenbildung (B, C), komplette Remission (D).

schmerzen beim Kauen und ausgedehnter Ulzerationen im Bereich der Kopfhaut beim Arzt vor. Eine Visusminderung oder Muskelschmerzen im Sinne einer Polymyalgia rheumatica wurden nicht berichtet. An der Kopfhaut fanden sich ausgedehnte Nekrosen (Abb. A). Beide Temporalarterien waren nicht schmerzhaft, aber kaum tastbar. Die BSG betrug $64 \mathrm{~mm} / \mathrm{h}$, der CRP-Wert $45 \mathrm{mg} / \mathrm{l}$. Unter der Diagnose einer Kopfhautnekrose als Komplikation einer Riesenzellarteriitis wurde der Mann mit $60 \mathrm{mg} / \mathrm{d}$ Prednisolon behandelt.

Im Verlauf der folgenden Monate ging die Symptomatik zurück. Auch die Kopfhautläsionen heilten unter tiefer Narbenbildung langsam ab (Abb. B, C). Die Prednisolon-Dosis wurde alle vier Wochen um $10 \mathrm{mg}$ reduziert, bis eine Erhaltungsdosis von $20 \mathrm{mg} / \mathrm{d}$ erreicht war. AnschlieBend erfolgte ein langsames Ausschleichen der Dosis.

Kopfhautnekrosen gehören zu den seltenen und potenziell lebensbedrohlichen Komplikationen einer Riesenzellarteriitis. Eine frühzeitige Diagnosestellung und Behandlung sind äußerst wichtig.

Prof. Dr. med. H. S. FüeßI

- Akram Q, ChinoyH (qasim.akram@gmail.com). Scalp necrosis associated with giant-cell arteritis. NEngl J Med. 2016;374:e6 